\title{
New multivalued fixed point results in cone $b$-metric spaces
}

Zhe Chu, Xianjiu Huang*, Xiaoyi Liu

Department of Mathematics, Nanchang University, Nanchang, 330031, Jiangxi, P. R. China.

Communicated by P. Kumam

\begin{abstract}
In this paper, we give a fixed point theorem for multivalued mappings in a cone $b$-metric space without the assumption of normality on cones and generalize some attractive results in recent literature. (c)2016 All rights reserved.
\end{abstract}

Keywords: Fixed points, multivalued mappings, cone $b$-metric spaces.

2010 MSC: 47H10, 54H25.

\section{Introduction}

The Banach contraction theorem [1] is a very popular tool in solving existence problems of fixed points and plays an important role in several branches of mathematics. Nadler [9] gave its set-valued form in his classical paper on multivalued contractions. He used the concept of Hausdorff metric which is defined by

$$
H(A, B)=\max \left\{\sup _{y \in B} d(y, A), \sup _{x \in A} d(x, B)\right\}
$$

for $A, B \in C B(X)$ and $d(x, B)=\inf _{y \in B} d(x, y)$, where $C B(X)$ denotes the collection of all nonempty closed bounded subsets of $X$.

Kikkawa and Suzuki [6] gave a generalization of Nadle's fixed point theorem and proved the following theorem:

\footnotetext{
${ }^{*}$ Corresponding author

Email addresses: chuzhe@email.ncu.edu.cn (Zhe Chu), xjhuangxwen@163.com (Xianjiu Huang), 1210371418@qq.com (Xiaoyi Liu)
} 
Theorem 1.1 ([6]). Define a strictly decreasing function $\varphi:[0,1) \rightarrow\left(\frac{1}{2}, 1\right]$ such that $\varphi(t)=\frac{1}{1+t}$. Let $(X, d)$ be a complete metric space and $T: X \rightarrow C B(X)$ be a multivalued mapping. Assume that there exists $a \in[0,1)$ such that

$$
\varphi(a) d(x, T x) \leq d(x, y) \Rightarrow H(T x, T y) \leq a d(x, y)
$$

for all $x, y \in X$. Then there exists $v \in X$ such that $v \in T v$.

In 2009, Mot and Petrusel [8], presented the result of [6] for locally contractive mappings, in the context of complete metric spaces.

Huang and Zhang [3] introduced the concept of cone metric space as a generalization of a metric space. Rezapour and Hamlbarani [10] generalized the results of [3] for the case of a cone metric space without the normality in cone. Many authors worked on it (see [5]). Cho et al. [2] invented the Hausdorff distance function on cone metric spaces and generalized the result of [7] for multivalued mappings.

In this article we give a generalization of Theorem 1.1 to the case of cone $b$-metric spaces by using Hausdorff distance function. Finally, we give an example to support our main theorem.

\section{Preliminaries}

Let $E$ be a real Banach space and $P$ be a subset of $E$. By $\theta$ we denote the zero element of $E$. The subset $P$ of $E$ is called a cone if and only if:

(i) $P$ is closed, nonempty, and $P \neq\{\theta\}$;

(ii) $a, b \in R, a, b \geq 0, x, y \in P \Rightarrow a x+b y \in P$;

(iii) $P \bigcap(-P)=\{\theta\}$.

For a given cone $P \subseteq E$, we define a partial ordering $\preceq$ with respect to $P$ by $x \preceq y$ if and only if $y-x \in P ; x \prec y$ will stand for $x \preceq y$ and $x \neq y$, while $x \ll y$ will stand for $y-x \in$ int $P$, where int $P$ denotes the interior of $P$. The cone $P$ is said to be solid if it has a nonempty interior.

Definition 2.1 ([4]). Let $X$ be a nonempty set and $r \geqslant 1$ be a given real number. A function $d: X \times X \rightarrow E$ is said to be a cone $b$-metric if the following conditions hold:

(i) $\theta \preceq d(x, y)$ for all $x, y \in X$ and $d(x, y)=\theta$ if and only if $x=y$;

(ii) $d(x, y)=d(y, x)$ for all $x, y \in X$;

(iii) $d(x, z) \preceq r[d(x, y)+d(y, z)]$ for all $x, y, z \in X$.

The pair $(X, d)$ is called a cone $b$-metric space.

Example 2.2. Let $X=R, E=R^{n}$ and $P=\left\{\left(x_{1}, x_{2}, \ldots, x_{n}\right) \in R^{n}: x_{i} \geq 0(1 \leq i \leq n)\right\}$, we define $d: X \times X \rightarrow E$ as

$$
d(x, y)=\left(|x-y|^{p}, a_{1}|x-y|^{p}, \ldots, a_{n-1}|x-y|^{p}\right),
$$

where $a_{i}(i=1, \ldots, n-1)$ and $p>1$ are constants. It is easy to see that $(X, d)$ is a cone $b$-metric space with the coefficient $r=2^{p-1}$.

Remark 2.3. It is obvious that any cone metric space must be a cone $b$-metric space. Moreover, cone $b$-metric spaces generalize cone metric spaces, $b$-metric spaces and metric spaces.

Definition $2.4\left([4)\right.$. Let $(X, d)$ be a cone $b$-metric space, $x \in X,\left\{x_{n}\right\}$ be a sequence in $X$. Then

(i) $\left\{x_{n}\right\}$ converges to $x$ whenever for every $c \in E$ with $\theta \ll c$ there is a natural number $n_{0}$ such that $d\left(x_{n}, x\right) \ll c$ for all $n \geq n_{0}$. We denote this by $\lim _{n \rightarrow \infty} x_{n}=x$;

(ii) $\left\{x_{n}\right\}$ is a Cauchy sequence whenever for every $c \in E$ with $\theta \ll c$ there is a natural number $n_{0}$ such that $d\left(x_{n}, x_{m}\right) \ll c$ for all $n, m \geq n_{0}$; 
(iii) $(X, d)$ is complete cone $b$-metric if every Cauchy sequence in $X$ is convergent.

Remark 2.5 ([5]). The results concerning fixed points and other results, in case of cone spaces with nonnormal solid cones, cannot be provided by reducing to metric spaces, because in this case none of the conditions of Lemmas $1-4$ in [3] hold. Further, the vector cone metric is not continuous in the general case, i.e., from $x_{n} \rightarrow x, y_{n} \rightarrow y$ it can not follow that $d\left(x_{n}, y_{n}\right) \rightarrow d(x, y)$.

Lemma $2.6([4)$. Let $(X, d)$ be a cone b-metric space. The following properties are often used while dealing with cone b-metric spaces in which the cone is not necessarily normal.

(i) If $u \preceq v$ and $v \ll w$, then $u \ll w$;

(ii) If $\theta \preceq u \ll c$ for each $c \in$ int $P$, then $u=\theta$;

(iii) If $a \preceq b+c$ for each $c \in$ int $P$, then $a \preceq b$;

(iv) If $\theta \preceq d\left(x_{n}, x\right) \preceq b_{n}$ and $b_{n} \rightarrow \theta$, then $x_{n} \rightarrow x$;

(v) If $a \preceq \lambda a$, where $a \in P$ and $0<\lambda<1$, then $a=\theta$;

(vi) If $c \in$ int $P, \theta \preceq a_{n}$ and $a_{n} \rightarrow \theta$, then there exists $n_{0} \in N$ such that $a_{n} \ll c$ for all $n>n_{0}$.

\section{Main result}

According to [2], we denote by $C B(X)$ the family of nonempty closed bounded subsets of $X$, and

$$
\begin{gathered}
s(p)=\{q \in E: p \preceq q\} \text { for } p \in E, \\
s(a, B)=\bigcup_{b \in B} s(d(a, b))=\bigcup_{b \in B}\{x \in E: d(a, b) \preceq x\} \text { for } a \in X \text { and } B \in C B(X) .
\end{gathered}
$$

For $A, B \in C B(X)$, we define

$$
s(A, B)=\left(\bigcap_{a \in A} s(a, B)\right) \cap\left(\bigcap_{b \in B} s(b, A)\right) .
$$

Lemma 3.1. Let $(X, d)$ be a cone $b$-metric space with a cone $P$. For $x, y \in X$ and $y \in B \subseteq X$, if $d(x, y) \preceq a$, then $a \in s(x, B)$.

We start with the following lemma and remark which will be used to prove our main result. (in particular when dealing with cone $b$-metric spaces in which the cone need not be normal).

Lemma $3.2([2,11])$. Let $(X, d)$ be a cone $b$-metric space and $P$ a cone in Banach space $E$. Then we have:

(i) Let $p, q \in E$. If $p \preceq q$, then $s(q) \subset s(p)$.

(ii) Let $x \in X$ and $A \in C B(X)$. If $\theta \in s(x, A)$, then $x \in A$.

(iii) Let $q \in P$ and $A, B \in C B(X)$ and $a \in A$. If $q \in s(A, B)$, then $q \in s(a, B)$.

(iv) For all $q \in P$ and $A, B \in C B(X)$ we have $q \in s(A, B)$ if and only if there exist $a \in A$ and $b \in B$ such that $d(a, b) \preceq q$.

Remark $3.3([2])$. Let $(X, d)$ be a cone $b$-metric space. If $E=R$ and $P=[0,+\infty)$, then $(X, d)$ is a $b$-metric space. Moreover, for $A, B \in C B(X), H(A, B)=\inf s(A, B)$ is the Hausdorff distance induced by $d$. Also, $s(\{x\},\{y\})=s(d(x, y))$ for all $x, y \in X$.

Now, we start with the main result of this paper.

Theorem 3.4. Let $(X, d)$ be a complete cone b-metric space with the coefficient $r \geq 1$ and cone $P$, and let $T: X \rightarrow C B(X)$ be a multivalued mapping. If there exists a function $\varphi:[0,1) \rightarrow\left(\frac{1}{2}, 1\right]$ defined by $\varphi(t)=\frac{1}{1+t}$, we assume that there exists $u \in[0,1)$ such that

$$
\frac{1}{\varphi(u)} d(x, y) \in s(x, T x) \Rightarrow u d(x, y) \in s(T x, T y)
$$

for all $x, y \in X$. Then there exists $v \in X$ such that $v \in T v$. 
Proof. Let $x_{0} \in X$ be an arbitrary element. Since $T x_{0} \in C B(X), T x_{0}$ is non-empty, there exists some $x_{1} \in T x_{0}$. Since

$$
d\left(x_{0}, x_{1}\right) \preceq \frac{1}{\varphi(u)} d\left(x_{0}, x_{1}\right),\left(\varphi(u) \in\left(\frac{1}{2}, 1\right]\right),
$$

by Lemma 3.1 we have

$$
\frac{1}{\varphi(u)} d\left(x_{0}, x_{1}\right) \in s\left(x_{0}, T x_{0}\right)
$$

Thus we get

$$
u d\left(x_{0}, x_{1}\right) \in s\left(T x_{0}, T x_{1}\right),
$$

so by Lemma 3.2 (iv), we can take $x_{2} \in T x_{1}$ such that

$$
d\left(x_{1}, x_{2}\right) \preceq u d\left(x_{0}, x_{1}\right) .
$$

Now, since

$$
d\left(x_{1}, x_{2}\right) \preceq \frac{1}{\varphi(u)} d\left(x_{1}, x_{2}\right)
$$

again by Lemma 3.1 we have

$$
\frac{1}{\varphi(u)} d\left(x_{1}, x_{2}\right) \in s\left(x_{1}, T x_{1}\right)
$$

This implies

$$
u d\left(x_{1}, x_{2}\right) \in s\left(T x_{1}, T x_{2}\right),
$$

and again by Lemma 3.2 (iv), there exists some $x_{3} \in T x_{2}$ such that

$$
d\left(x_{2}, x_{3}\right) \preceq u d\left(x_{1}, x_{2}\right) .
$$

By induction we get an iterative sequence $\left\{x_{n}\right\}_{n \geq 0}$ in $X$ with $x_{n+1} \in T x_{n}$, such that

$$
d\left(x_{n}, x_{n+1}\right) \preceq u d\left(x_{n-1}, x_{n}\right) .
$$

If $x_{n}=x_{n+1}$ for some $n \in N$, then $T$ has a fixed point. Assume that $x_{n} \neq x_{n+1}$, then for all $n \in N$,

$$
d\left(x_{n}, x_{n+1}\right) \preceq u d\left(x_{n-1}, x_{n}\right) \preceq u^{2} d\left(x_{n-2}, x_{n-1}\right) \preceq \cdots \preceq u^{n} d\left(x_{0}, x_{1}\right) .
$$

Now for $m>n$, applying Definition 2.1 (iii) to triple

$$
\left\{x_{n}, x_{n+1}, x_{m}\right\},\left\{x_{n+1}, x_{n+2}, x_{m}\right\}, \cdots,\left\{x_{m-2}, x_{m-1}, x_{m}\right\},
$$

we obtain

$$
\begin{aligned}
d\left(x_{n}, x_{m}\right) & \preceq r\left[d\left(x_{n}, x_{n+1}\right)+d\left(x_{n+1}, x_{m}\right)\right] \\
& \preceq r d\left(x_{n}, x_{n+1}\right)+r^{2}\left[d\left(x_{n+1}, x_{n+2}\right)+d\left(x_{n+2}, x_{m}\right)\right] \\
& \preceq \cdots \\
& \preceq r d\left(x_{n}, x_{n+1}\right)+r^{2} d\left(x_{n+1}, x_{n+2}\right)+\cdots+r^{m-n-1}\left[d\left(x_{m-2}, x_{m-1}\right)+d\left(x_{m-1}, x_{m}\right)\right] \\
& \preceq r d\left(x_{n}, x_{n+1}\right)+r^{2} d\left(x_{n+1}, x_{n+2}\right)+\cdots+r^{m-n-1} d\left(x_{m-2}, x_{m-1}\right)+r^{m-n} d\left(x_{m-1}, x_{m}\right) .
\end{aligned}
$$

Since $d\left(x_{n}, x_{n+1}\right) \preceq u^{n} d\left(x_{0}, x_{1}\right)$, we get

$$
\begin{aligned}
d\left(x_{n}, x_{m}\right) & \preceq\left(r u^{n}+r^{2} u^{n+1}+\ldots+r^{m-n} u^{m-1}\right) d\left(x_{0}, x_{1}\right) \\
& \preceq r u^{n}\left(1+(r u)+\cdots+(r u)^{m-n-1}\right) d\left(x_{0}, x_{1}\right) \\
& =\frac{r u^{n}\left(1-(r u)^{m-n}\right)}{1-r u} d\left(x_{0}, x_{1}\right) \rightarrow \theta \text { as } n \rightarrow \infty .
\end{aligned}
$$

Now, according to Lemma 2.6 (i) and (vi), we get that for a given $\theta \ll c$ there exists $m_{0} \in N$ such that 


$$
d\left(x_{m}, x_{n}\right) \ll c \text {, for all } m, n>m_{0} .
$$

This means that $\left\{x_{n}\right\}$ is Cauchy sequence in $(X, d)$. Since $(X, d)$ is a complete cone $b$-metric space, there exists $v \in X$ such that $x_{n} \rightarrow v$. Therefore, for $\theta \ll c$, there exists $k_{0} \in N$ such that for $n \geq k_{0}$ we get $d\left(v, x_{n+1}\right) \ll \frac{c}{2 r}$, and $d\left(x_{n}, v\right) \ll \frac{c}{2 r}$.

Now we will prove $v \in T v$. For this let us consider that from (3.1) there exists $u \in[0,1)$ such that

$$
\frac{1}{\varphi(u)} d\left(x_{n}, v\right) \in s\left(x_{n}, T x_{n}\right) \Rightarrow u d\left(x_{n}, v\right) \in s\left(T x_{n}, T v\right) .
$$

By Lemma 3.2 (iii) there exists some $x_{n+1} \in T x_{n}$ such that

$$
u d\left(x_{n}, v\right) \in s\left(x_{n+1}, T v\right) \in \bigcup_{x \in T v} s\left(d\left(x_{n+1}, x\right)\right),
$$

so there exists some $v_{n} \in T v$ such that

$$
u d\left(x_{n}, v\right) \in s\left(d\left(x_{n+1}, v_{n}\right)\right)
$$

It gives

$$
d\left(x_{n+1}, v_{n}\right) \preceq u d\left(x_{n}, v\right) \preceq d\left(x_{n}, v\right) .
$$

Now consider

$$
\begin{aligned}
d\left(v, v_{n}\right) & \preceq r\left[d\left(v, x_{n+1}\right)+d\left(x_{n+1}, v_{n}\right)\right] \\
& \preceq r d\left(v, x_{n+1}\right)+r d\left(x_{n}, v\right) \\
& \ll \frac{c}{2}+\frac{c}{2}=c \text { for all } n \geq k_{0},
\end{aligned}
$$

which means $v_{n} \rightarrow v$, since $T v$ is closed we have $v \in T v$. This completes the proof.

Corollary 3.5. Let $(X, d)$ be a complete cone $b$-metric space with the coefficient $r \geq 1$ and cone $P$, and let $T: X \rightarrow C B(X)$ be a multivalued mapping. Assume that there exists $u \in[0,1)$ such that

$$
u d(x, y) \in s(T x, T y)
$$

for all $x, y \in X$. Then there exists $v \in X$ such that $v \in T v$.

Corollary $3.6([6])$. Let $(X, d)$ be a complete cone b-metric space with the coefficient $r \geq 1$ and cone $P$, and let $T: X \rightarrow C B(X)$ be a multivalued mapping. Let $\varphi:[0,1) \rightarrow\left(\frac{1}{2}, 1\right]$ be the strictly decreasing function defined by $\varphi(t)=\frac{1}{1+t}$. Assume that there exists $a \in[0,1)$ such that

$$
\varphi(a) d(x, T x) \leq d(x, y) \Rightarrow H(T x, T y) \leq a d(x, y)
$$

for all $x, y \in X$. Then there exists $v \in X$ such that $v \in T v$.

Corollary $3.7([7])$. Let $(X, d)$ be a complete cone b-metric space with the coefficient $r \geq 1$ and cone $P$, and let $T: X \rightarrow C B(X)$ be a multivalued mapping. Assume that there exists $u \in[0,1)$ such that

$$
H(T x, T y) \leq u d(x, y)
$$

for all $x, y \in X$. Then there exists $v \in X$ such that $v \in T v$.

Remark 3.8. Theorem 3.4 is a generalization of Theorem 1.1 of Kikkawa and Suzuk [6] from metric spaces to cone metric spaces without using normality of $P$. Moreover, we use the notion $s(T x, T y)$ which analogue the concept $H(T x, T y)$ in cone $b$-metric spaces. 
Example 3.9. Let $X=[0,1], E=C_{R}^{1}[0,1]$ with the norm $\|f\|=\|f\|_{\infty}+\left\|f^{\prime}\right\|_{\infty}$ and $P=\{x \in E: x(t) \succeq \theta\}$, where $\theta(t)=0$ for all $t \in X$, then $P$ is a non-normal cone. Define $d: X \times X \rightarrow E$ as follows:

$$
(d(x, y))(t)=|x-y|^{2} e^{t} .
$$

Let $T: X \rightarrow C B(X)$ be a multivalued mapping and $T x=\left[0, \frac{x}{30}\right]$.

Then $(X, d)$ is a cone $b$-metric space. In fact, we can get that Definition 2.1 (i) and (ii) are obviously satisfied. Now, we show Definition 2.1 (iii) are satisfied.

For $x, y, z \in X$, set $u=x-z, v=z-y$, so $x-y=u+v$. From the inequality

$$
(a+b)^{2} \leq 2\left(a^{2}+b^{2}\right) \text { for all } a, b \geq 0,
$$

we have

$$
\begin{aligned}
& |x-y|^{2}=|u+v|^{2} \leq 2\left(|u|^{2}+|v|^{2}\right)=2\left(|x-z|^{2}+|z-y|^{2}\right) \\
& |x-y|^{2} e^{t} \leq 2\left(|x-z|^{2} e^{t}+|z-y|^{2} e^{t}\right)
\end{aligned}
$$

which implies that

$$
d(x, y) \preceq r[d(x, z)+d(y, z)] \text { with } r=2>1 .
$$

We take $u=\frac{1}{9} \in[0,1)$, then $\varphi(u)=\frac{9}{10}$. Since $T x$ is non-empty, there exists $y \in T x$ such that

$$
s(x, T x)=s(d(x, y))=s\left(|x-y|^{2} e^{t}\right) .
$$

Since

$$
|x-y|^{2} e^{t} \leq \frac{1}{\varphi(u)} d(x, y)=\frac{10}{9}|x-y|^{2} e^{t},
$$

we get

$$
\frac{10}{9}|x-y|^{2} e^{t} \in s(x, T x) .
$$

From $T x=\left[0, \frac{x}{30}\right]$, for $x<y$,

$$
s(T x, T y)=s\left(\left|\frac{x}{30}-\frac{y}{30}\right|^{2} e^{t}\right) .
$$

Since

$$
\left|\frac{x}{30}-\frac{y}{30}\right|^{2} e^{t} \leq \frac{1}{3^{2}}|x-y|^{2} e^{t}=\frac{1}{9}|x-y|^{2} e^{t},
$$

we get

$$
\frac{1}{9}\left(|x-y|^{2} e^{t}\right) \in s\left(\left|\frac{x}{30}-\frac{y}{30}\right|^{2} e^{t}\right) .
$$

Therefore, for $u=\frac{1}{9} \in[0,1)$, we have

$$
\frac{1}{\varphi(u)} d(x, y) \in s(x, T x) \Rightarrow u d(x, y) \in s(T x, T y) .
$$

Moreover, 0 is the fixed point. Thus all the conditions of Theorem 3.4 are satisfied.

\section{Acknowledgements}

The authors thank the editor and the referees for their valuable comments and suggestions. This article was supported by the National Natural Science Foundation of China(11461043, 11361042 and 11326099) and supported partly by the Provincial Natural Science Foundation of Jiangxi, China (20142BAB201005). 


\section{References}

[1] S. Banach, Sur les opérations dans les ensembles abstraits et leur application aux équations intégrales, Fund. Math., 3 (1922), 133-181. 1

[2] S. H. Cho, J. S. Bae, Fixed point theorems for multi-valued maps in cone metric spaces, Fixed Point Theory Appl., 2011 (2011), 7 pages. 1, 3, 3.2, 3.3

[3] L. G. Huang, X. Zhang, Cone metric spaces and fixed point theorems of contractive mappings, J. Math. Anal. Appl., 332 (2007), 1468-1476. 1, 2.5

[4] N. Hussain, M. H. Shah, KKM mappings in cone b-metric spaces, Comput. Math. Appl., 62 (2011), $1677-1684$. $2.1,2.4,2.6$

[5] S. Janković, Z. Kadelburg, S. Radenović, On cone metric spaces: a survey, Nonlinear Anal., 74 (2011), $2591-2601$. $1,2.5$

[6] M. Kikkawa, T. Suzuki, Three fixed point theorems for generalized contractions with constants in complete metric spaces, Nonlinear Anal., 69 (2008), 2942-2949. 1, 1.1, 1, 3.6, 3.8

[7] N. Mizoguchi, W. Takahashi, Fixed point theorems for multivalued mappings on complete metric spaces, J. Math. Anal. Appl., 141 (1989), 177-188. 1. 3.7

[8] G. Mot, A. Petrusel, Fixed point theory for a new type of contractive multivalued operators, Nonlinear Anal., 70 (2009), 3371-3377. 1

[9] S. B. Nadler, Multi-valued contraction mappings, Pacific J. Math., 30 (1969), 475-478. 1

[10] S. Rezapour, R. Hamlbarani, Some notes on the paper cone metric spaces and fixed point theorems of contractive mappings, J. Math. Anal. Appl., 345 (2008), 719-724. 1]

[11] W. Shatanawi, V. Ćojbaśić Rajic, S. Radenović, A. Al-Rawashdeh, Mizoguchi-Takahashi-type theorems in tvs-cone metric spaces, Fixed Point Theory Appl., 2012 (2012), 7 pages. 3.2 